Vol. 9

No. 17

Enero - Junio de 2015

\title{
El crecimiento empresarial una herramienta fundamental para la reducción de la pobreza
}

\author{
The business growth: A fundamental tool for poverty reduction
}

\footnotetext{
Patricia Rodriguez Vélez

Maestría en Dirección y Administración Coordinador Académico, Universidad Antonio Nariño Seccional Palmira-Valle, Colombia patricrodriguez@uan.edu.co

Paola Andrea Salazar Valencia Especialista en Gerencia Docente de tiempo completo, Universidad Pontificia Bolivariana Seccional Palmira-Valle, Colombia paolaandrea.salazar@upb.edu.co

Tipología: Artículo de Reflexión Fecha de Recibido: Febrero 06 de 2015 Fecha de Aceptación: Abril 28 de 2015

Para citar este artículo:

Rodriguez, V. P., y Salazar, V. P. (2015). El crecimiento empresarial una herramienta fundamental para la reducción de la pobreza, Clío América, 9 (17), 77 - 84
}

Resumen: En este documento se estudian las tendencias de pobreza y desigualdad en Colombia con el fin de establecer los factores determinantes en su variación; tanto la medición como la disminución de éste flagelo depende de innumerables factores. Tomando casos empresariales reales, la intervención privada a través de la responsabilidad social y observando estadísticas de gasto público social, se propone analizar la incidencia de este tipo de intervenciones en las variaciones positivas de las cifras de pobreza y desigualdad en Colombia, las limitaciones de las políticas públicas y el rumbo a seguir de la responsabilidad social. Con estas referencias se va a estudiar el mecanismo que puede incidir de manera contundente en la reducción de pobreza y desigualdad, y en el incremento del nivel de vida de la población. La metodología utilizada es revisión documental de bibliografía especializada.

Palabras clave: Pobreza; Desigualdad; Política Pública; Responsabilidad Social Empresarial; Teoría Neoclásica; Teoría Neoliberal; Competitividad.

JEL: 015, 020, 040

Abstract: This paper deals with poverty and inequality tendencies in Colombia in order to establish the decisive factors in their variation. Both measuring and decreasing of this problematic depends of many factors. Taking real enterprise cases, private intervention through social responsibility and checking statistics of social state expenditure, it is proposed to establish the incidence of these kinds of interventions in the positive variations of poverty and inequality figures in Colombia, the limitations of state policies and the following course of social responsibility. These references is to study the mechanism which can affect in a strong way in the decreasing of poverty and inequality and increasing of life level of population. The methodology used was a documentary revision of specialized bibliography.

Keywords: Poverty; Growth Economics; State Policy; Enterprise Social Responsibility; Neoclassical Theory; Neoliberal Theory; Competitiveness. 


\section{Introducción}

El sector privado, desde su perspectiva meramente económica y en búsqueda de competitividad, ha implementado mecanismos que suelen resultar nefastos para la sociedad en el largo plazo ocasionando la disminución de los salarios reales. Joseph Stilgitz (2012), premio nobel de economía, argumenta que el $1 \%$ de la población posee la riqueza que el $99 \%$ de la población necesita. Los empresarios deben asumir a conciencia el flagelo de la pobreza, ésta debe hacer parte de sus objetivos principales, conectando sus esfuerzos, sentimientos y emociones no solo con el progreso económico sino también con el social, apartándose de la concepción errada de que lo social le compete solo al estado, como si el progreso económico y el progreso social fuesen excluyentes entre sí, cuando se pueden disminuir los índices de pobreza y desigualdad, mediante la integración de gobiernos y empresarios (Carmona López \& Richards , 2011).

Sin embargo, tal como lo afirma Antonio Vives (2013), "Una de las contribuciones de la empresa a la sociedad más directas y tradicionales es a través del empleo directo. Es su responsabilidad social considerar a los trabajadores primero como seres humanos antes que como instrumentos de producción" (pág. 20). Si se logra que ésta valiosa contribución impacte a la población vulnerable, mediante la creación de empleos con sentido humano, el impacto iría más allá que el simple incremento de la producción, se fomentaría el consumo para familias cuyo único activo es su fuerza laboral. Es ésta una de las afirmaciones primordiales del estudio económico neoclásico, pues Según Adam Smith, (Citado por Lüchinger) "la fuente del bienestar es el factor trabajo, sin olvidar que no hay nación que pueda florecer y prosperar si la mayoría vie en la pobreza y la miseria". (pág. 33)

La problemática cobra un matiz mucho más complejo cuando se introducen conceptos de desigualdad, ya que tal como lo afirma Alfredo Macías Vásquez (2014): “La pobreza y la desigualdad son fenómenos distintos, pero relacionados. En general, una mayor desigualdad suele implicar niveles más elevados de pobreza". (pág. 102).
El Programa de las Naciones Unidas para el Desarrollo PNUD (2012), tiene consolidados diversidad de indicadores sociales a nivel nacional y ha creado un índice de Desarrollo Humano (IDH) que mide la calidad de vida de la población de los países. La medida se expresa en una escala de 0 a 1.0 según tres indicadores fundamentales: Esperanza de vida de mujeres y hombres al nacer (Salud), Nivel de escolarización de la población (Educación) y Producto Interno Bruto por habitante (Ingresos).

Según la Organización de las Naciones Unidas ONU (2011), Colombia ocupa el puesto 79 entre los 169 países clasificados por el (IDH), según Jairo Agudelo Taborda (2011), Director de la Escuela Latinoamericana de Cooperación y Desarrollo los indicadores de salud, educación e ingresos se combinan con otros como: equidad de género, respeto de derechos humanos, participación cultural y política de la población.

Si el IDH (2010), se combina con el Coeficiente de Gini que mide la concentración de la riqueza en un país con escala de 0.0 a 1.0 donde 0.0 sería la sociedad equitativa y 1.0 la más inequitativa y desigual, el IDH colombiano cae a la cifra de 0.492 pasando del puesto 79 al 97 entre 169 países objeto del informe; este dato demuestra que Colombia es el séptimo país más desigual del mundo, con un coeficiente de Gini de 0.60 comparable sólo con Namibia, Angola, Botswana, Belice, Islas Comores y Haití. Colombia pasó a ser en ese año el país más desigual de América Latina.

Se comprueban pues las afirmaciones de Thomas Piketty (2014):

“Desde sus orígenes, la economía política ha intentado estudiar científicamente, o cuando menos racionalmente, y de forma sistemática y metódica, cuál debe ser el papel ideal del Estado en la organización económica y social de un país, cuáles son las instituciones y políticas públicas que más nos acercan a una sociedad ideal" (pág. 645)

El propósito de la presente investigación es dimensionar el impacto de las intervenciones empresariales 
en las cifras de pobreza, las limitaciones de la implementación de las políticas públicas y el rumbo a seguir de las empresas referentes a la responsabilidad social, para generar dinámicas que puedan perdurar en el tiempo.

\section{Políticas públicas: Generalidades}

La política pública es el resultado de la decisión de la autoridad gubernamental, siempre en busca de un objetivo encaminado a resolver problemas de la sociedad y forjar un beneficio común, ya que el propósito fundamental de los gobiernos es garantizar niveles de vida estables y equitativos, permitir la movilidad social y la seguridad para el estado. Tanto las políticas públicas como sus objetivos no deben ser estáticos en el tiempo, deben cambiar para garantizar su eficiencia, sin perjudicar notablemente la consecución de sus propósitos en el corto plazo.

Generalmente los objetivos de política pública se distinguen entre dos grupos: los económicos y los de carácter social. Los económicos son los que están intimamente ligados al bienestar económico general, entre los que se destacan el crecimiento económico, el pleno empleo, la estabilidad de precios, la distribución equitativa de la renta y la riqueza 0 al menos reducción de desigualdades de renta existentes. Para la consecución de dichos objetivos el gobierno cuenta con instrumentos de política económica.

En cuanto a los objetivos de carácter social, en estos se integran normalmente todos aquellos que no son prioritariamente económicos y que se atienden con la aplicación de políticas sociales orientadas a mejorar o preservar el bienestar social, entre los cuales cabe destacar: la educación, la salud, la protección del medio ambiente y la seguridad interna y externa, es decir, los que se relacionan con el término: calidad de vida de la población.

En este orden de ideas, Isabel Ortíz (2007) expresa que las políticas sociales han sido utilizadas pragmáticamente por muchos gobiernos para conseguir el respaldo político de los ciudadanos, generar cohesión social y potenciar un mayor desarrollo económico. Las políticas sociales pueden superar el círculo vicioso de la pobreza y el atraso y crear un círculo virtuoso en el que el desarrollo humano y el empleo generen una mayor demanda interna (pág. 6).

Sin embargo, este único instrumento está siendo utilizado para favorecer a grupos élites de los países generando prebendas bajo la disminución de impuestos y otros mecanismos, con argumentaciones que se han refutado año tras año, a través de cifras alarmantes de pobreza, no sólo en Colombia sino también a nivel mundial, al respecto Stiglitz (2012) afirma:

Hemos creado una economía y una sociedad donde las grandes fortunas se amasan a través de la búsqueda de ingresos a través de transferencias directas desde el sector público a los ricos a través de normas que les permiten recaudar ingresos del resto de la sociedad (Stiglitz, 2012, p. 332).

Lo anterior concuerda con Piketty (2014) “Los multimillonarios poseían cerca de $0,4 \%$ de la riqueza privada mundial en 1987, y en 2013 poseían más de 1,5\%" (pág. 476) y de cierta manera explica por qué a pesar de la inversión social que establecen los países, el fenómeno de pobreza no disminuye y al contrario la pobreza extrema se acrecienta, el estado ha enfrentado ineficientemente las consecuencias nefastas que se presentan y la sociedad asume las consecuencias: altos indices de criminalidad, problemas sanitarios, menores niveles de educación y de cohesión social.

\section{Aplicación de políticas públicas en Colombia en los últimos cinco años}

La orientación ideológica del gobierno liberal 0 conservador, no siempre se reflejó en los planes de desarrollo implementados en Colombia, "gobiernos conservadores, como el de Pastrana, aplicaron políticas intervencionistas, mientras que gobiernos liberales, como el de Gaviria, han sido muy reacios a la intervención" (Fresneda, González, Cárdenas, \& Sarmiento, 2009).

En este contexto, la División de Desarrollo Social (2008) expone que el gran desafío que debieran 
abordar los países de América Latina y el Caribe, es colaborar en la conformación de lo que la CEPAL (2006) ha llamado marco de solidaridad integral. Este consiste en crear las condiciones necesarias para establecer instituciones en que se combinen en forma apropiada los diferentes mecanismos de financiamiento a fin de aplicar políticas que contribuyan realmente a disminuir la pobreza y la exclusión social. (p. 5).Para Hayek (Citado por Czarnecki, 2013) "La respuesta para combatir la pobreza es el incremento de la prosperidad en la sociedad", y para Para Becker (Citado por Czarnecki, 2013) "La gente debería tener un mínimo de los capitales humanos, por eso debería haber intervención del Estado para proporcionar el mínimo necesario sin disturbio del mercado" (pág. 184).

En este orden de ideas, la solución gubernamental actual para reducir la pobreza y la desigualdad y aumentar el índice de Desarrollo Humano en Colombia se evidencia en el documento: "Mensaje presidencial 2012, más empleo, menos pobreza y más seguridad; con solidez fiscal" publicado por el Ministerio de Hacienda, en el cual se detalla que el presupuesto general de la Nación (PGN) para la vigencia fiscal de 2012, y que asciende a $\$ 165,3$ billones de pesos, de los cuales se asignan para Inversión $\$ 34,0$ billones en 2012 y de este rubro el $42 \%$ se destina al pilar Igualdad de Oportunidades y Prosperidad Social, es decir, $\$ 14$ billones de pesos. (Ministerio de Hacienda, 2012).

Evidenciando estas cifras de inversión destinadas a mejorar las condiciones de vida de los colombianos, la consolidación de la paz y sostenibilidad ambiental también relacionados en el documento presidencial y del Ministerio de Hacienda y aclarando que estos gastos de inversión se han incrementado en un $3.9 \%$ en promedio anual, no existe una razón que explique porque el $34,1 \%$ de la población nacional se encuentra en la pobreza, según informe del grupo de expertos de la Misión para el Empalme de las Series de Empleo, Pobreza y Desigualdad (MESEP) presentado en mayo de 2012 (DANE, 2012).

La formulación del presupuesto se ha realizado con una cuidadosa priorización del gasto privilegiando el gasto público social tal como lo ordena la Constitución Política, protegiendo la inversión pública y considerando las disponibilidades fiscales de la Nación. (Ministerio de Hacienda, 2012, p.1). Según informe sobre Reducción de la pobreza en Colombia/ PNUD (2011), para Fresneda, González, Cárdenas \& Sarmiento (2009) el Gasto Público Social (GPS) es el que se destina a bienes y servicios que afectan el nivel de vida de los hogares. (pág. 38). En concordancia con las cifras del DANE y del Ministerio de Hacienda, Márquez (2007) afirma: "es poco probable que los gobiernos por sí solos puedan mejorar la situación de pobreza en que viven miles de millones de personas en todo el mundo. El reto para las empresas consiste en asumir un nuevo papel con iniciativas de mercado que generen inclusión" (pág. 59).

Al respecto Mauricio Cárdenas, (2007) afirma que el crecimiento económico, es decir, incremento del Producto Interno Bruto, debe considerarse el primer paso para la reducción de la pobreza, la empresa se convierte entonces en eje fundamental para la reducción de dicha problemática por la cual atraviesa el país y cuyo protagonista es la comunidad que enfrenta directamente el infortunio. Sin embargo, es necesario resaltar a Max Neef: "La capacidad económica no necesariamente genera una calidad de vida óptima ni ofrece la posibilidad de desarrollo humano, dado que la satisfacción de las necesidades básicas sólo son un eslabón en la cadena del logro del desarrollo humano" (Citado por Vélez Osorio, 2011) (pág. 1227). Para Max Neef "Las necesidades humanas son finitas y lo que cambia son los satisfactores y los seudo satisfactores de acuerdo con las culturas o con los momentos históricos que vive el ser humano. Dichas necesidades son existenciales y axiológicas" (Citado por Ríos Lasso \& Andrade Franco, 2009) (pág. 81), es decir que sí es posible eliminar el flagelo de la pobreza, mediante mecanismos de inclusión social que surjan de la empresa privada y que procuren disminuir la las preocupantes desigualdades que incluyen disparidades en materia de riqueza, marcadas asimetrías en los aspectos políticos, sociales, de oportunidades económicas y de poder. (Sen \& Kliksberg, 2007) (pág. 18).

Una de las formas más reconocidas para éste acercamiento e integración entre la empresa privada y la población ha sido el concepto de "Responsabilidad social" definido como el comportamiento que asu- 
men las empresas hacia la sociedad en beneficio del desarrollo sostenible. (Aguilera Castro \& Puerto Becerra, 2012).

\section{Responsabilidad social empresarial y su relación con la reducción de pobreza}

El concepto de Responsabilidad social se ha concebido desde diversos enfoques y en este sentido Aguilera Castro \& Puerto Becerra (2012) refieren cuatro dimensiones: la responsabilidad económica relacionada con la producción de bienes y servicios que la sociedad desea y puede adquirir; la responsabilidad legal que implica obedecer las leyes locales; la responsabilidad ética que exige cumplimiento de otras expectativas sociales no consignadas en la ley y que suelen estar relacionadas con lineamientos de conducta definidos; y finalmente la responsabilidad voluntaria que sugiere comportamientos adicionales y actividades que la sociedad considera deseables y que dictan los valores de la empresa.

En este orden de ideas la Responsabilidad Social Empresarial genera un factor diferenciador a las empresas que lo apliquen, pues la competencia en los mercados obliga generar estrategias que las diferencien de sus homologas para que el consumidor las elija. La Organización Internacional del Trabajo (OIT) también ha desarrollado el tema de RSE y lo ha definido como el conjunto de acciones que toman en consideración las empresas para que sus actividades tengan repercusiones positivas en la sociedad y que reafirman los principios y valores por los que se rigen.

Muhamad Yunus (2008) define que las “Empresas con Responsabilidad Social se han construido sobre las mejores intenciones, pero algunos directivos hacen mal uso de este concepto para generar beneficios para sus propias firmas. La filosofía pareciera ser: conseguir tantos beneficios como sea posible, incluso aunque sea necesario explotar a los más pobres, pero, entonces, donar una pequeña cantidad de los beneficios a causas sociales o crear una fundación que haga algo que favorezca a los intereses empresariales, y no debe olvidarse explicar a bombo y platillo lo generoso que es" (pág. 35).
Siguiendo ésta apreciación, la RSE no es espontanea, es un acto premeditado en busca de beneficios a la organización o sus accionistas y no contempla beneficios sociales o de impacto a la comunidad; además al ser la RSE un régimen impositivo por algunas reglamentaciones gubernamentales se pierde el objetivo inicialmente planteado pues el bienestar común y el desarrollo humano debe ser algo transversal en los procesos y la alta gerencia debe asumir el rol de asegurarse que su entorno se desarrolle y beneficie claramente de las ganancias derivadas de la explotación de recursos que pertenecen a la comunidad.

Transferir toda la responsabilidad de reducción de pobreza al estado es un acto por lo demás irresponsable y soñador. La historia nos demuestra que a pesar de todos los recursos destinados a apoyar causas sociales en dirección del mejoramiento de vida de la población, el mecanismo por sí solo no es suficiente.

Es necesario establecer proyectos que incluyan a la empresa privada desarrollando estrategias de responsabilidad para perfeccionar la relación de beneficios económicos y sociales generales. Estas estrategias pueden partir en la creación de empresa desde la pobreza, generar productos dirigidos y asequibles a la población vulnerable y determinar a los pobres como un mercado potencial no solo para que adquieran productos, sino como protagonistas en los procesos de creación y expansión empresarial. Procesos como éstos ya se han aplicado y los resultados han sido extraordinarios.

\section{Estudio de casos empresariales latinoamericanos que demuestran reducción de los indices de pobreza al integrarse la empresa a la solución del flagelo}

Las empresas son la principal fuente generadora de ingresos para todos los agentes económicos, genera ingresos al estado mediante el pago de impuestos, genera ingresos a los accionistas o propietarios a través de utilidades y también genera ingresos a las familias poseedoras del recurso humano, imprescindible en cualquier proceso productivo, sin mencionar 
que genera valor a toda su cadena productiva, desde proveedores hasta la logística de comercialización.

Las empresas a continuación mencionados demuestran que a pesar de seguir generando ingresos a los agentes, también han contribuido a disminuir la pobreza y desigualdad en cada uno de los países, sin arriesgar su supervivencia en el largo plazo.

\section{Estudio de Caso: Cemex.}

Márquez (2007), la cementera Cemex se percató, a finales de los años noventa, de la creciente demanda de cemento entre los consumidores de bajo ingreso de México y decidió entenderlos mejor. En 1998 creó la iniciativa "Patrimonio Hoy", para facilitar la compra de cemento y la construcción en los barrios. Para vencer la desconfianza reclutaron a mujeres de las zonas, que conocían a los clientes. Establecieron un esquema de créditos para la compra del cemento con base en un sistema de ahorro informal típico de las zonas pobres de América Latina llamado «tanda» en México y «san» en Venezuela (p. 60).

Con esta iniciativa Cemex aborda un problema extendido en los países en desarrollo: la falta y la precariedad de la vivienda. "Patrimonio Hoy" ha ayudado a unas 75 mil familias a construir 44 mil habitaciones de diez metros cuadrados. Más allá de eso brinda una posibilidad de mejora antes impensable para muchos. La iniciativa de Cemex fortalece, además, atributos culturales positivos como la solidaridad y la participación (Prahalad, 2005, p. 62).

Cabe resaltar que Cemex no disminuyó los precios de sus productos, los gastos extras generados a raíz de la contratación de personal para asesorar a las familias, fue mínimo debido a que un solo colaborador se encargaba de al menos 500 familias, lo que ha hecho Cemex es generar un valor agregado para que las familias siempre consuman sus productos $y$ no los de la competencia.

\section{Estudio de Caso: Gas natural Ban.}

En 1992 la empresa Gas Natural Ban obtuvo una licencia para prestar el servicio de distribución de gas natural en la Zona Norte de la provincia de Buenos
Aires, por un plazo de 35 años. En ese momento, la cantidad de habitantes conectados a las redes de gas era relativamente reducida, debido a los altos costos de conexión; pero la empresa observó que el mercado potencial estaba en los segmentos bajos y medio-bajos (Márquez, 2007, p. 61).

El uso artesanal del gas resultaba más costoso y por tanto no todos tenían acceso. La empresa aceptó en 2001 una propuesta de la ONG Fundación Pro Vivienda Social para conectar en red a la comunidad, la cual inmediatamente se agrupó en la asociación Comunidad Organizada y se construyó la red de distribución de gas. (Márquez, 2007, p. 61).

Este modelo empresarial es un ejemplo en el cual se ha dejado de pensar en los pobres como víctimas y se han generado estrategias que podrían ser utilizadas por otros sectores para hacer negociaciones rentables. De esta manera serían cuatro mil millones de pobres formando la gran custodia de comercio y prosperidad a nivel global (Prahalad, 2005, p.40).

\section{Estudio de Caso: Big Kola}

Ningún banquero quería trabajar con la familia Añaños hasta hace diez años. Ahora, que son los principales productores de bebidas gaseosas de América Latina, los banqueros hacen cola para hacer negocios con ellos. (Córdova, 2009, p. 31). Quince años después de su inicio, los analistas de Wall Street calculan que la empresa familiar Big Kola, tiene ingresos anuales que superan los trescientos millones de dólares, y que su competencia, en el Perú, Ecuador, Venezuela y México, está creando serios problemas a los gigantes norteamericanos de Coca-Cola y Pepsi Cola, (Córdova, 2009, p. 31).

Con éste ejemplo de creación de empresa se puede disipar definitivamente el concepto de que es imposible el desarrollo empresarial desde la pobreza, además se demuestra que no solo ésta creación de empresa puede reducir el flagelo de quienes logran emprendimiento exitoso, sino que se convierte en fuente generadora de ingresos para muchos otros colaboradores contratados, generando productos asequibles para la población más vulnerable haciendo que su nivel de vida mejore. 


\section{Conclusión y Discusión}

Para superar la pobreza se requiere incrementar la tasa de participación en la actividad económica y la productividad de los miembros en edad activa de las familias pobres, combinando capacitación y un especial apoyo a las mujeres a fin de posibilitar su participación laboral. Al respecto, los ejemplos empresariales mencionados en el presente documento, son una pequeña y significativa muestra de que los programas que cada una ha generado, no solo generan incrementos productivos y económicos, también han logrado potenciarlas, generarles valor agregado y mayor recordación en la comunidad, pues sus programas se han traducido en un incremento salarial e inclusión para las familias más vulnerables, contribuyendo así a la reducción de problemáticas sociales.

Las empresas deben dejar de pensar en los sectores marginados como sectores que no aportan al proceso productivo, al contrario en su afán de generar movilidad social y escapar de las trampas de pobreza, las familias de estos sectores son un factor generador de riqueza a través del trabajo. Además, cabe resaltar que a pesar de sus limitaciones económicas, también tienen necesidades de productos y aquí hay una fuente importante para la innovación en bienes que estén a su alcance.

Es evidente que a pesar de las bien intencionadas políticas sociales aplicadas histórica y actualmente, éstas no han sido eficientes cuando se mide el Índice de Desarrollo Humano de la Población. Anualmente se destinan recursos que solo atienden problemáticas urgentes, y es ésta una de las principales limitaciones de las políticas públicas, mientras no se generen tácticas que integren los objetivos sociales con los objetivos empresariales, el problema no se reducirá de manera contundente.

La reducción de la pobreza no puede enfocarse solamente al aumento de rentas nominales, sino que debe abordar un aumento en la calidad de vida de la población y éste contempla la relación del individuo con su entorno el cual le garantiza de cierta manera el cumplimiento de objetivos sociales destinados a mejorar su calidad de vida de una manera prolongada en el tiempo.

Por lo tanto, la pobreza y la desigualdad no se puede concebir a perpetuidad, lo que realmente interesa a un individuo es su bienestar a lo largo de la vida y no solo en un momento en particular, de ahí la importancia de garantizar instrumentos que permitan al individuo la movilidad social.

Daniel Córdova (2009) afirma que la sociedad percibe a las empresas como entidades que se aprovechan de los pobres, y que el papel del Estado debería ser, quitarles parte de su riqueza para atender a los más necesitados. Esto da la sensación de que vivimos en un mundo estático, en el que los pobres no se pueden volver ricos, en el que los pobres no pueden hacer empresa y dejar de ser microempresarios para ser empresarios medianos y grandes. Esta percepción obedece a la falta de continuidad en los procesos enfocados a la disminución de pobreza (p.25).El mecanismo de Responsabilidad Social, que últimamente ha tomado fuerza y es muy reconocido en el ámbito económico, es un buen punto de partida para vincular la empresa con la sociedad, pues bajo la dimensión de responsabilidad voluntaria se efectúan todas aquellas acciones y comportamientos adicionales que la sociedad considera deseables pues representa un beneficio y dictan los valores empresariales.

La lucha contra la pobreza requiere una cohesión entre las actividades gubernamentales y las actividades empresariales, siendo ésta posible cuando existe un sentido más fuerte de solidaridad que permita a las empresas generar estrategias de inclusión y fomento de procesos productivos sostenibles que generen ingresos a los distintos grupos que componen la sociedad nacional, enfocados especialmente a la población más vulnerable.

Por lo anterior, disminuir significativamente el problema de pobreza en Colombia es posible cuando el crecimiento empresarial sea asociado con la visión de desarrollo a escala humana, generando estrategias de negocios que logren integrar los aspectos económicos y sociales y que impacten positivamente 
a la sociedad, haciendo parte de las soluciones sostenidas. Estas acciones tienen una mayor garantía de éxito dentro de una sociedad más equitativa, más participativa e integrada de manera contundente a los objetivos sociales fundamentales garantizando la calidad de vida de la población que exige y merece soluciones que le aseguren un estilo de vida digno en igualdad de condiciones para todos.

\section{Referencias Bibliográficas}

Aguilera Castro, A., \& Puerto Becerra, D. (2012). Crecimiento empresarial basado en la responsabilidad social . Pensamiento y Gestión, 1-26.

Carmona López, R. J., \& Richards, H. (2011). La pobreza como eje de la ética en un mundo globalizado. Ciencias Estratégicas, 101-108.

Cárdenas, M. (2007). Introducción a la economía colombiana . Bogotá: Alfaomenga.

Czarnecki, L. (2103). La concepción de la pobreza en el modelo neoliberal. ¿Cómo entender la lucha contra la pobreza en México? Frontera Norte, 179- 191.

Cordova, D. (2009). Lecciones de los pobres: empresa privada y progreso social. Revista De Economía Y Derecho, 23-35.

DANE. (7 de Julio de 2012). DANE. Obtenido de www.dane. gov.co/files/investigaciones/condiciones_vida/pobreza/ declaracion_expertos_pobreza_2012.pdf

División de Desarrollo Social. (2008). Superar la pobreza mediante la inclusión social. Recuperado el 8 de Julio de 2013, de División Desarrollo Social CEPAL: http:// www.eclac.cl/cgi-bin/getProd.asp?xml=/publicaciones/ xml/8/32358/P32358.xml\&xsl=/dds/tpl/p9f.xsl\&base=/ dds/tpl/top-bottom.xsl

Fresneda, 0., González, J. I., Cárdenas, M. E., \& Sarmiento, L. (2009). Fundación Unviersidad Autónoma de Colombia. Obtenido de http://www.fuac.edu.co/download/ AREAS/10ipp.pdf
Lüchinger, R. (2014). Adam Smith. En B. Köhler, Los 12 economistas más importantes de la hisotria/ compilador (págs. 21-33). Bogotá: Norma.

Macías Vazquez, A. (2014). CRECIMIENTO, DESIGUALDAD Y POBREZA: ESTADO DE LA CUESTIÓN. (Spanish). Revista de Economía Institucional, 16 (31), 101-126.

Márquez, P. (2007). Negocios para la inclusión: Un nuevo paradigma empresarial . Debates IESA, 59-63.

Ministerio de Hacienda. (15 de Marzo de 2012). Ministerio de Hacienda. Obtenido de www.minhacienda.gov.co/portal/ page/portal/HomeMinhacienda/presupuestogeneraldelanacion/ProyectoPGN/2012/MP\%20principal\%202012.pdf

Ortíz, I. (2007). Desarrollo. Naciones Unidas. Recuperado el 2013, de http://esa.un.org/techcoop/documents/socialpolicy_spanish.pdf

Piketty, T. (2014). El capital en el siglo XXI. Bogotá: Fondo de Cultura Económica .

Prahalad, C. K. (2005). La Riqueza en la Base de la Pirámide. Bogotá: Norma.

Ríos Lasso, C. A., \& Andrade Franco, D. F. (2009). Abordaje del desarrollo humano en los planes de desarrollo. Cali: Universidad Santiago de Cali.

Sen, A., \& Kliksberg, B. (2007). Primero la gente. Barcelona: Deusto.

Stiglitz , J. E. (2012). El precio de la desigualdad. Bogotá: Taurus.

Vives, A. (2013). Empleo y emprendimiento como responsabilidad social de las empresas. (Spanish). GCG: Revista de Globalización, Competitividad \& Gobernabilidad, 7 (3), 16-33. doi:10.3232/GCG.2013.V7.N3.0

Vélez Osorio, I. M. (2011). El desarrollo humano en Colombia desde la perspectiva de Manfred Max Neef. Global Conference on Business and Finance Proceedings, 1226- 1236.

Yunus, M. (2008). Un mundo sin pobreza. Madrid: Huertas Industrias Gráficas. 